\title{
Catalyst design with porous functional structures
}

\author{
J. Van Noyen, S. Mullens, F. Snijkers \& J. Luyten \\ Flemish Institute of Technological Research (VITO), \\ Department of Materials Technology, Belgium
}

\begin{abstract}
The chemical industry is experiencing important changes. The driving force for these changes is a growing need to improve competitiveness and consolidate market positions while complying with the regulations for safeguarding human health, and the environment. Currently, what is known as "green chemistry" or "sustainable technology" is at the heart of the changes the chemical industry is undergoing.

Catalysis and materials science will play an important role in this new approach. One domain with specific relevance is porous ceramics and metals, substrates with pores sizes ranging from vacancies at the atomic level to macro pores with sizes of millimeters. There are plenty of emerging applications for porous functional components. Each application will specify the window of properties of the porous material.

A technology assessment of the developed porous materials and powder processing techniques for their use as catalyst or membrane system will be presented, limited to inorganic porous materials which can be synthesized by dry and wet powder processing methods. The applications overview for porous materials is focused on macroporous components with a designed functional coating.
\end{abstract}

Keywords: porous materials, powder processing techniques, catalysis, structured reactors, catalytic membrane reactors, coating techniques.

\section{Introduction}

It is widely acknowledged that there is a growing need for more environmentally acceptable processes in the chemical industry. This trend towards what has become known as "green chemistry" or "sustainable technology" necessitates a 
shift to new concepts that minimize waste at source, avoid the use of toxic and/or hazardous substances and are energy-efficient. To realize these needs specific tools have to be developed. Catalysis is generally accepted as a strong pillar within the green chemistry approach. Ceramic catalysts and catalyst supports constitute the largest market segment in high tech ceramics industry outside electronic ceramics. In 2005 the market was estimated \$ 2.03 billion, with an expected increase of 5\% per year to $\$ 3.16$ billion in 2009 [1].

Catalysts are the key for sustainable development in the chemical process industry. They aid the synthesis of products in a resource protective way, with less consumption of energy, and in some cases, without any formation of by-products or waste. Catalysts, especially applied in a structured way, play an important role in the so-called integrated approach to environmental protection, which, among others, includes integration of various process operations such as chemical reaction, separation, heat exchange, and momentum transfer. The result of process intensification is the reduction of investment costs, which is often combined with significant energy recovery and space saving. Besides others, such savings are possible with the use of multifunctional reactors (such as monolith or membrane reactors, catalytic filters), reactive distillation columns, etc. [2].

\section{Structured catalysts vs packed beds}

Heterogeneous catalytic reactions account for over $85 \%$ of industrial chemical processes. They are involved in a large variety of processes ranging from refining over fine and specialty chemistry to environmental protection and sustainable chemistry [3]. Several processing and coating routes and related characterization techniques have been developed in order to manage the various application domains and window of properties. Classical heterogeneous catalysts consist of an active component, a binder, and several additives. These mixtures can be shaped in several ways, for instance by pressing, extrusion or spray drying. Depending on the shaping technique, wet or dry processing is required. Several shapes can be obtained, such as spheres, cylinders, tablets, lobed structures,... with dimensions of tens of $\mu \mathrm{ms}$ up to several millimeters. These catalyst bodies can be used in fixed bed reactors, or in fluidized bed reactors. Several reviews on classical catalytic processes and the selection of a proper catalyst system can be found in [4-6].

Besides the well established classical processes with random fixed or fluidized beds, structured reactors have been developed in both chemical and automotive industries since the early 1970s. Structured internals can play a very important role and allow solutions that were previously impossible [7]. They allow a unique way of achieving process intensification in the chemical processand refining industry. Several functions or processes are designed to occur simultaneously in multifunctional reactors. The aim is an optimal integration of mass, heat and momentum transfer within a single reactor vessel [8]. A structured reactor contains a macro-structured internal which can be made of ceramics, metal or carbon, situated inside the reactor. It can be considered as an intensified form of a packed bed reactor [9]. The advantage of such a structured 
reactor is that it may be designed in full detail up to the local surroundings of the catalyst, allowing ultimate precision. In addition, structured reactors are flexible with respect to different length scales, i.e., diffusion lengths, voidage,... Different manufacturing routes have been developed to produce such macroporous support structures.

Specific surface area and catalytic activity are obviously of crucial importance for obtaining a good catalyst with high activity and stability. Functionalization of the structured reactor internal is therefore an essential step. Reviews on the manufacture of macroporous supports can be found in [7, 10]. An intrinsic difficulty associated with the adoption of structured catalysts in reactors for chemicals production is the limited volume fraction of catalytically active material as compared to packed beds of catalyst pellets (structured catalyst $\sim 20 \%$ compared to a packed bed $\sim 60 \%$ ). In this respect, however, one should consider that the effectiveness factors of the thin catalytic washcoats in structured catalysts are generally greater than those of pellets, and typically close to one.

To achieve comparable catalyst loadings with that of a randomly packed bed, either a high geometrical area of the structured internal or an integral structured catalyst is a prerequisite. If the catalyst is coated on the surface of the structured internal, then the stability and resistance of the coating to adverse conditions such as high temperature, temperature shocks, and high pressures needs to be considered. To enhance the catalytic activity the support, i.e. from an innovative support for catalyst to a true catalytic system, advanced surface engineering is applied: phase inversion, etching of the support surface, coating with zeolites and/or composites with catalytically-active compounds (transition metals, defect sites,...) applying sol gel, co-precipitation, electrolytical methods, texturing the surface with lithography,... Different methods to apply a catalytic layer onto a support have been reviewed $[10,11]$.

Packed beds show good activity due to high catalyst loading and longer residence times. However, packed beds often show incomplete catalyst wetting and poor mass transfer rates, due to undesirable effects in the fluid dynamics [9]. This can for example lead to hot spots and catalyst deactivation. Pressure drop over packed beds is generally high. Numerous products are commercialized as porous beads, which can be loaded in different reactor designs. The catalyst can be produced relatively cheap [12]. Despite efforts to ameliorate the mechanical properties (based on nanopowders, the addition of a second phase, doping or novel sintering techniques), problems like attrition remain key in packed bed technology. In view of the rapid improvements in the area of catalysis, leading to highly active catalyst particles, the issues discussed above will only become more pressing. Major challenges can be foreseen in the more classical active bed designs.

Monolithic catalysts take advantage of their favourable pressure behavior; and often find application in automotive applications and off-gas treatment. Both for gas-solid as gas-liquid reactions they can offer significant advantages compared to more traditional multiphase reactors. Low pressure drop compared to solid packed beds is the major advantage. Processes which require conversion 
of large volumes of gas mixtures, such as hydrogenations, the lower pressure drop over monoliths can result in lower investment- and working costs for the compressor. In comparison with slurry reactors the separation of the catalyst is avoided. Because in monolithic catalysts very thin layers of catalyst can be applied, an increase in selectivity by the avoiding of detrimental sequential reactions is possible. For fast reactions the costs for the expensive noble metal catalysts can remain limited. However, for very exothermal reactions efficient heat transfer can become a problem (e.g. hot spots), which can limit the use of such reactor systems $[7,9,13]$.

Foam catalyst structures can also be used for very similar reaction types as monolithic catalysts, as many of the advantages of the honeycomb type reactors also apply for this type of catalyst supports. On top of that, good mixing is assured by the tortuous path the reactants have to follow through the packing [14]. However, design flexibility is low because of the random structure of foam.

Within the field of structured packings, KATAPAK ${ }^{\circledR}$, a structured packing developed by Sulzer Chemtech is generally considered as state-of-the-art technology. This packing is often used in catalytic distillation, where reaction and separation are carried out in one process. Depending on design and support material used, mass- and heat transfer properties are generally good. For catalytic applications however a coating or catalyst section still needs to be applied. These types of packings can be used for reactive distillations, or as total oxidation catalyst carriers. [9, 15].

The three-dimensional fiber deposition (3DFD) of a ceramic or metallic structure is a new and innovative support preparation technique (also known as Robocasting). It combines the major advantages of the packings listed above, such as low pressure drop, good mass- and heat transfer, good mixing. On top of that, the technique allows making a catalyst structure by design rather than chance, in this way allowing very flexible and efficient use of catalyst in the reactor volume.

This manufacturing technique comprises the extrusion of a highly viscous metallic or ceramic paste through a tin nozzle, mounted on a $\mathrm{CNC}$ machine or $\mathrm{x}, \mathrm{y}, \mathrm{z}$-table. The porous architecture is built layer-by-layer, as is shown in figure $1[10,16]$.

The major pros and cons of the different techniques are listed in table 1.
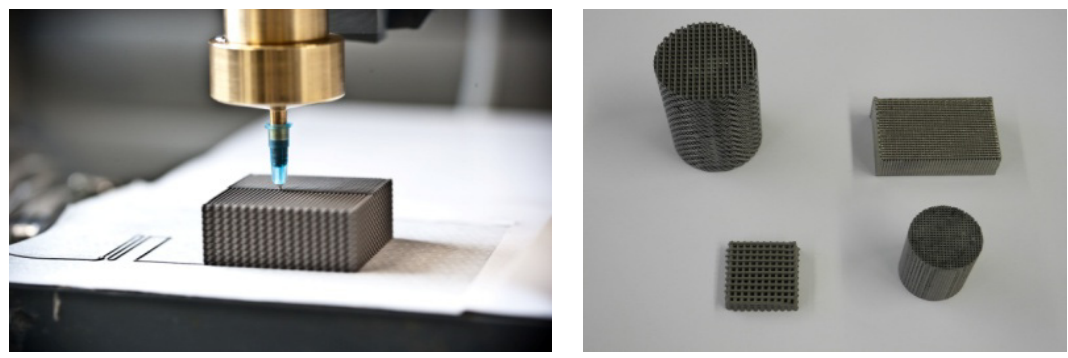

Figure 1: [Left] apparatus for three-dimensional fiber deposition; [Right] examples of parts built by 3DFD. 
Table 1: Overview of different catalyst shaping techniques in view of relevant parameters for catalytic applications.

\begin{tabular}{|c|c|c|c|c|c|}
\hline Parameter & $\begin{array}{c}\text { Packed } \\
\text { bed }\end{array}$ & Monolith & Foam & $\begin{array}{l}\text { Structured } \\
\text { packing }\end{array}$ & 3DFD \\
\hline Radial mass flow & fair & good & good & good & good \\
\hline $\begin{array}{l}\text { Radial heat } \\
\text { exchange }\end{array}$ & fair & no & good & good & good \\
\hline $\begin{array}{l}\text { Tortuosity of fluid } \\
\text { flow }\end{array}$ & yes & no & yes & yes & yes \\
\hline Pressure drop & high & low & low & low & low \\
\hline $\begin{array}{c}\text { Geometrical } \\
\text { macroporosity }\end{array}$ & $35-40 \%$ & $70-90 \%$ & $60-90 \%$ & n.a. & $\begin{array}{l}\text { up to } \\
90 \%\end{array}$ \\
\hline Design flexibility & low & low & low & medium & high \\
\hline
\end{tabular}

Table 2: $\quad$ Overview of selected applications of structured catalysts.

\begin{tabular}{|c|c|c|c|}
\hline Reaction & Support & Characteristics & Reference \\
\hline $\begin{array}{c}\text { catalytic } \\
\text { combustion }\end{array}$ & ceramic foam & $\begin{array}{c}\text { hydrocarbons } \\
\text { preformed shapes }\end{array}$ & [17] \\
\hline partial oxidation & $\begin{array}{l}\text { ceramic foam and } \\
\text { honeycomb }\end{array}$ & $\begin{array}{l}\text { hydrocarbons } \\
\text { selective } \\
\text { low contact times }\end{array}$ & {$[18]$} \\
\hline $\begin{array}{c}\text { selective } \\
\text { hydrogenation }\end{array}$ & honeycomb & $\begin{array}{l}\text { cordierite monolith } \\
\text { coated with } \mathrm{Pd} \\
\text { impregnated alumina }\end{array}$ & [19] \\
\hline $\begin{array}{c}\text { automotive } \\
\text { exhaust }\end{array}$ & $\begin{array}{l}\text { ceramic foam and } \\
\text { honeycomb }\end{array}$ & $\begin{array}{l}\text { three way catalyst, } \\
\text { deNOx, soot filter }\end{array}$ & [20] \\
\hline $\begin{array}{c}\text { ethylbenzene to } \\
\text { styrene }\end{array}$ & honeycomb & $\begin{array}{l}\text { improved heat- and } \\
\text { mass transfer }\end{array}$ & {$[21]$} \\
\hline Fischer-Tropsch & honeycomb & $\begin{array}{l}\text { coated cordierite and } \\
\text { metallic honeycomb }\end{array}$ & [22] \\
\hline $\begin{array}{l}\text { anthraquinone } \\
\text { autoxidation }\end{array}$ & honeycomb & $\begin{array}{l}\text { reinforced amorphous } \\
\text { silica, Pd catalyst }\end{array}$ & [23] \\
\hline $\begin{array}{c}\text { 1-propanol + } \\
\text { propionic acid to } \\
\text { propyl } \\
\text { propionate }\end{array}$ & Katapak ${ }^{\circledR}$ & $\begin{array}{l}\text { reactive distillation, } \\
\text { amberlyst } 46 \text { catalyst }\end{array}$ & [24] \\
\hline steam reforming & ceramic foam & $\begin{array}{l}\text { foam particles, pressure } \\
\text { drop down } 25 \% \text {, heat } \\
\text { transfer up } 10 \%\end{array}$ & {$[25]$} \\
\hline $\begin{array}{l}\text { ammonia } \\
\text { oxidation }\end{array}$ & ceramic foam & $\begin{array}{c}800-1100^{\circ} \mathrm{C} \\
\text { selective } \\
\text { no hot spots } \\
\text { less Pt }\end{array}$ & [26] \\
\hline
\end{tabular}


A non exhaustive overview of catalytic reactions where structured catalysts have been used is given in Table 2. Further reviews and examples can be found [1, 4-7]. The application of structured packings for reactions with strong diffusion limitations, pressure drop constraints and heat transfer limitations will be the subject of intensified research in the next few years because of their obvious benefits of random (packed) beds.

\section{Ceramic membranes}

Ceramic membranes have a high thermal, chemical and mechanical resistance compared to polymeric membranes. These advantages can outweigh their higher intrinsic costs for certain applications, ensuring their share in the future growth of membrane technology [10,27]. Membrane reactors integrate conversion and separation in one process step, thus allowing significant process intensification. The integration of membranes in a (catalytic) reactor allows to control the addition and distribution of one reactant in a controlled fashion in order to achieve optimal concentration profiles resulting in higher yields and achieve improved temperature control and safety. Alternatively, one of the products can be selectively removed from a process, typically used to shift equilibria and get round thermodynamics [28]. The concept of membrane reactors dates back to the 1960 s, and since that time a large number of patents and papers have been published on that subject, at the intersection between catalysis, materials science and chemical engineering. The interest in membrane technology has been largely demonstrated at laboratory scale, i.e. for oxygen separation, hydrogenation, dehydrogenation, decomposition and oxidative reactions including partial oxidation and oxidative coupling of methane [28, 29]. Though at present only small industrial applications exist, the concept has yet a large opportunity to find widespread industrial application. Commercialization of such devices however, requires achieving the often incompatible aims of high performance, chemical stability, as well as optimal stacking, cost, sealing concepts, etc.

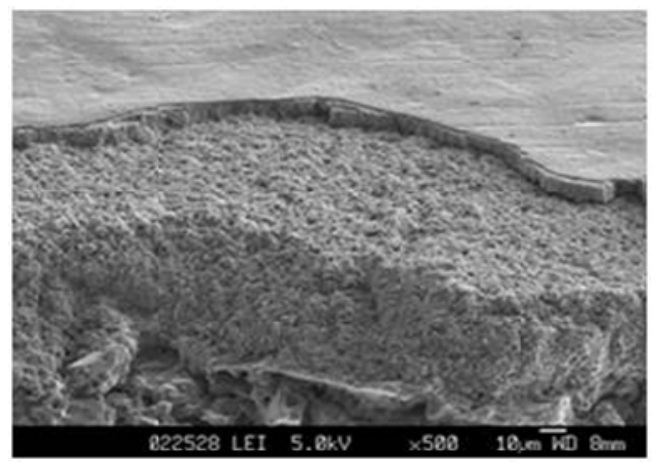

Figure 2: A multilayer ceramic membrane showing the different layers. 
Tubes, hollow fibers and plates are the most common shapes. The macroporous substrates with pores of $5-10 \mu \mathrm{m}$ and a porosity of $30-50 \%$ offer the mechanical strength of the membrane. Mostly, tubes are produced by extrusion, hollow fibers are produced by spinning, and plates by pressing or tape casting. On top of the support, a functional layer is deposited to separate components from process streams, as shown in figure 2. Optimization of membranes is directed towards a combination of high flux of components through the membrane, with a high selectivity and thus separation.

A separate category is the dense membranes, the proton- and oxygen conductors (see figure 3). The main transport mechanism is mobility of vacancies of $\mathrm{H}$ - or $\mathrm{O}$-ions at elevated temperatures. This ensures a $100 \%$ selectivity of the membrane. Performance of these membranes can be increased with a modified surface layer, i.e. by increasing roughness or applying a catalyst onto the membrane surface. These gas separating membranes, which currently draw a lot of attention in the field of energy applications, can also be of benefit for chemical reactors, by making catalytic membrane reactors using hollow fiber technology [30-31].

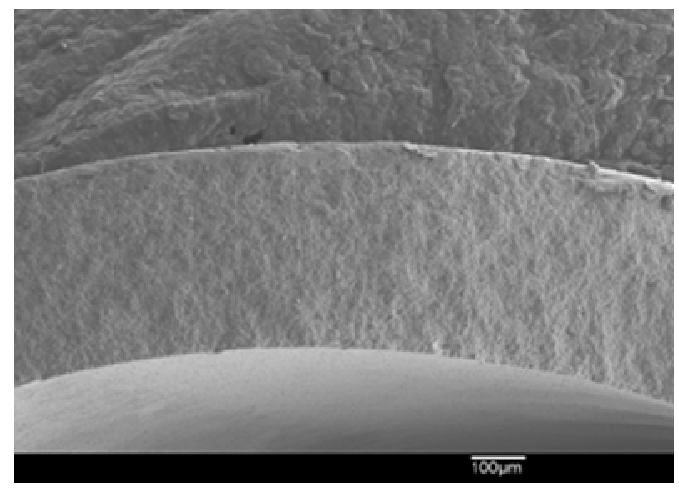

Figure 3: Dense oxygen separating hollow fibre membrane produced by a spinning technique.

\section{Conclusion}

There are plenty of emerging applications for porous components in different catalytic reactions. In order to cope with this large application domain and window of properties, several processing and coating routes and related characterization techniques have been developed enabling the manufacture of materials with a wide variety of porous architectures, pore size distribution (from a few angstroms to several millimeters), interconnectivity, pore gradients or layers with different pores sizes. This contribution has given an overview on the processing techniques which play a role in the design of inorganic materials for many applications. 
Process intensification will be of key importance for the greening of our chemical industry, with optimization of heat- and mass transfer, and integration of separations as major fields for improvement.

Clearly, there is potential in ceramics and ceramic design techniques for catalysis and process intensification. Structured reactor internals allow for a flexible design of a catalytic structure, with flexibility down to the nanometer level by the functionalization of the surface. Porous functional structures, also taking ceramic membranes into account, allow integration of reaction and separation. For some applications they will certainly overcome the disadvantage of lower catalyst hold-ups and higher costs over their obvious advantages of higher reaction rates selectivities, lower pressure drop and better heat transport when compared to the traditional packed bed reactors.

\section{References}

[1] Keane, M.A., Ceramics for catalysis. Journal of Materials Science, 38, pp. 4461-4675, 2003.

[2] Buchholz S., Future manufacturing approaches in the chemical and pharmaceutical industry. Chemical Engineering and Processing, 49(10), pp. 993-995, 2010.

[3] Centi, G. \& Perathoner S., Integrated Design for Solid Catalysts in Multiphase Reactions. Cattech, 7(3), 78-89, 2003.

[4] Le Page, J.F., Applied Heterogeneous Catalysis, Editions Technip: Paris, pp. 1-286, 1987.

[5] Rase, H.F., Handbook of Commercial Catalysts, CRC Press: London, New York and Washington, pp. 1-482, 2000.

[6] Deutschmann, O., Knözinger, H., Kochloefl K. \& Turek T., Heterogeneous Catalysis and Solid Catalysts. Ullmann's Encyclopedia of Industrial Chemistry, Wiley-VCH Verlag GmbH: Weinheim, Electronic version, 2009.

[7] Scheffler, F., Claus, P., Schimpf, S., Lucas, M. \& Scheffler, M., Heterogeneously Catalyzed Processes with Porous Cellular Ceramic Monoliths (Chapter 5.4). Cellular Ceramics: Structure, Manufacturing, Properties and Applications, ed. M. Scheffler \& P. Colombo, Wiley-VCH GmbH: Weinheim, pp. 454-483, 2005.

[8] Dautzenberg, F.M. \& Mukherjee, M., Process intensification using multifunctional reactors. Chemical Engineering Science, 56, pp. 251-267, 2001.

[9] Pangarkar, K., Schildhauer, T.J., van Ommen J.R., Nijenhuis, J., Kapteijn, F. \& Moulijn J.A., Structured packings for multiphase catalytic reactors. Industrial \& Engineering Chemical Research, 47, pp. 3720-3751, 2008.

[10] Luyten, J., Mullens S. \& Thijs, I., Designing with pores - Synthesis and Applications. KONA Powder and Particle Journal, 28, pp. 1-12, 2010.

[11] Meille, V., Review on methods to deposit catalysts on structured surfaces. Applied Catalysis A: General, 315, pp. 1-17, 2006. 
[12] Holt, E.M., The properties and forming of catalysts and adsorbents by granulation. Powder Technology, 140, pp. 194-202, 2004.

[13] Tomasic, V \& Jovic, F., State-of-the-art in the monolithic catalysts/reactors. Applied Catalysis A: General, 311, pp. 112-121, 2006.

[14] Richardson, J.T., Demue, D. \& Hung, J.-K., Properties of ceramic foam catalyst supports: mass and heat transfer. Applied Catalysis A: General, 250, pp. 319-329, 2003.

[15] Pfeuffer, B., Kunz, U., Hofmann, U., Turek, T. \& Hoell D., Heterogeneous reactive extraction for an intensified alcohol process. Catalysis Today, 147S, pp. S357-S361, 2009.

[16] Nuyts, P., Luyten, J., Mullens, S., Schroeven, M. \& Rombouts, M., The 3D fiber deposition technique for producing porous periodic metals and ceramics. Proceed. ISuP - 2010 conference, Bruges, pp. 1-4, 2010.

[17] Richardson, J.T., Peng, Y. \& Remue, D., Properties of ceramic foam catalyst supports: pressure drop. Applied Catalysis A: General, 204, pp. 19$32,2000$.

[18] Torniainen, P.M., Chu, X. \& Schmidt, L.D., Comparison of monolithsupported metals for the direct oxidation of methane to syngas. Journal of Catalysis, 146(1), pp. 1-10, 1994.

[19] Smits, H.A., Stankiewicz, A., Glasz, W.C., Fogl, T.H.A. \& Moulijn, J.A., Selective three-phase hydrogenation of unsaturated hydrocarbons in a monolithic reactor. Chemical Engineering Science, 51(11), pp. 3019-3025, 1996.

[20] Li, L., Zhang, F. \& Guan, N., Ir/ZSM-5/cordierite monolith for catalytic NOx reduction from automobile exhaust. Catalysis Communications, 9(3), pp. 409-415, 2008.

[21] Liu, W., Addiego, W.P. \& Sorensen, C.M., Monolith Reactor for the Dehydrogenation of Ethylbenzene to Styrene. Industrial \& Engineering Chemistry Research, 41(13), pp. 3131-3138, 2002.

[22] Visconti, C.G., Tronconi, E., Lietti, L., Groppi, G., Forzatti, P., Cristiani, C., Zennaro, R. \& Rossini S., An experimental investigation of FischerTropsch synthesis over washcoated metallic structured supports. Applied Catalysis A: General, 370(1-2), pp. 93-101, 2009.

[23] Edvinsson Albers, R., Nyström, M., Siverström, M., Sellin, A., Dellve, A.C., Andersson, U., Herrmann, W. \& Berglin, T., Development of a monolith-based process for $\mathrm{H} 2 \mathrm{O} 2$ production: from idea to large-scale implementation. Catalysis Today, 69(1-4), pp. 247-252, 2001.

[24] Kotora, M., Buchaly, C., Kreis, P., Górak, A. \& Markoš, J., Reactive distillation - experimental data for propyl propionate synthesis. Chemical Papers, 62(1), pp. 65-69, 2008.

[25] Twigg, M.V. \& Richardson, J.T., Theory and Applications of Ceramic Foam Catalysts, Chemical Engineering Research and Design, 80(2), pp. 183-189, 2002.

[26] Campbell, L.E., Catalyst for the production of nitric acid by the oxidation of ammonia, US005256387, pp. 1-5, 1994. 
[27] Buekenhoudt, A., Kovelvski, A., Luyten, J. \& Snijkers, F., Basic aspects in inorganic membrane preparation (chapter 1.11). Comprehensive Membrane Science and Engineering, ed. Drioli, E. \& Giorno, L., Elsevier: Amsterdam, pp. 217-252, 2010.

[28] Ravanchi, M.T., Kaghazchi T. \& Kargari, A., Application of membrane separation processes in petrochemical industry: a review. Desalination, 235, pp. 199-244, 2009.

[29] Caro, J., Schiestel, T., Werth, S., Wang, H. \& Noack, M., Can inorganic membranes compete with organic ones? Perovskite hollow fibres for $\mathrm{O}_{2}$ separation and support $\mathrm{H}_{2}$-selective membranes. Desalination, 199, pp. 365-367, 2006.

[30] Caro, J., Catalysis in micro-structured membrane reactors with nanodesigned membranes. Chinese Journal of Catalysis, 29(11), pp. 1169-1177, (2008).

[31] Kovalevsky, A., Buysse, C., Snijkers, F., Buekenhoudt, A., Luyten, J., Kretzschmar, J. \& Lenaerts, S., Oxygen exchange-limited transport and surface activation of $\mathrm{Ba} 0.5 \mathrm{Sr} 0.5 \mathrm{Co} 0.8 \mathrm{Fe} 0.2 \mathrm{O} 3-\delta$ capillary membranes. Journal of Membrane Science, 368(1-2), pp. 223-232, 2011. 